\title{
Research on the Spatial Composition of Private Gardens in Southern Fujian from the Cultural Perspective
}

\author{
Mengyu Zhang ${ }^{1, a}$ \\ ${ }^{I}$ Department of Art and Design, The Jimei university, Jimei, Xiamen,Fujian, China \\ azmy971101@163.com
}

\begin{abstract}
Starting from the cultural perspective of southern Fujian, this article analyzes the spatial composition of traditional private gardens in southern Fujian and its diverse culture. The southern Fujian region was exposed to Western culture earlier, and the gentry from the Central Plains moved south. The collision between culture and culture had a huge impact on the construction of private gardens in the region, presenting diverse cultural connotations and aesthetic styles. This research integrates and summarizes the recorded materials, and investigates some private garden sites in southern Fujian. At the same time, it analyzes and summarizes the historical overview, the status quo of the remains, and the changes in spatial composition from a cultural perspective.
\end{abstract}

Keywords: Southern Fujian, Traditional garden, Space composition, culture

\section{THE CULTURAL BACKGROUND AND CURRENT SITUATION OF PRIVATE GARDENS IN SOUTHERN FUJIAN}

The southern part of Fujian is called "Southern Fujian", which mainly includes Xiamen, Zhangzhou, Quanzhou and other surrounding counties. The formation of the culture in southern Fujian has extremely profound historical connotations, and the scope of cultural generation is relatively large. Due to the troubled wars in ancient times, the scholars and people from the north continued to move south, and their culture, economy, and politics were integrated into the development context of Fujian ${ }^{[1]}$. Xia Zhangquan, the location of the Golden Triangle of Southern Fujian, became Fujian Province due to its superior geographical location and pleasant climate. The place with the most developed economy and culture has become the cradle of the culture of southern Fujian, which also provides a good environment for the generation of traditional private gardens, making it a gathering place for private gardens in Fujian.

The private home forest is one of the three main types of classical Chinese gardens ${ }^{[2]}$.The germination and development of traditional private gardens in southern Fujian are inseparable from the integrated and diverse southern Fujian culture, the superior Central
Plains, Wuyue culture, and later the absorption of Nanyang culture and Western culture. For example, the Shuzhuang Garden on Gulangyu Island in Xiamen is a relatively well-preserved and renovated private garden in Xiamen. The owner Lin Shuzhuang went to Taiwan when he was young. When he settled on Gulangyu Island, he built Shuzhuang Garden in accordance with the style of Jiangnan gardens. The characteristics of local gardens in southern Fujian are also unique in the beautiful style of Jiangnan gardens. There are many such gardens in southern Fujian. Some of them were built by ancient literati officials, or with literati color, southward migration culture, highlighting the spatial artistic conception and humanistic connotation of the garden; there are also overseas Chinese or immigrant population under the impact of modern foreign culture. The built Chinese and Western gardens, Western-style villas, and the integration of Western culture have given the unique exotic features of southern Fujian private gardens. It is an innovation of traditional Chinese gardening techniques and techniques by overseas Chinese in southern Fujian in modern times.

The unique geographical environment and comfortable climatic environment in southern Fujian have promoted the construction and development of private gardens. Unfortunately, with the change of dynasties and eras, the improper protection and manual 
rectification of gardens in the early years caused many gardens to lose their originality. Meaningful. The existing private gardens are not well intact. For example, the Qingyuan Academy in Zhangzhou only has rockery ponds and covered bridges; the buildings in the Meishi Mountain House in Quanzhou have been destroyed, leaving only a few rockery. But even so, the artistic and cultural values of private gardens in southern Fujian still exist and are recognized and inherited by the world.

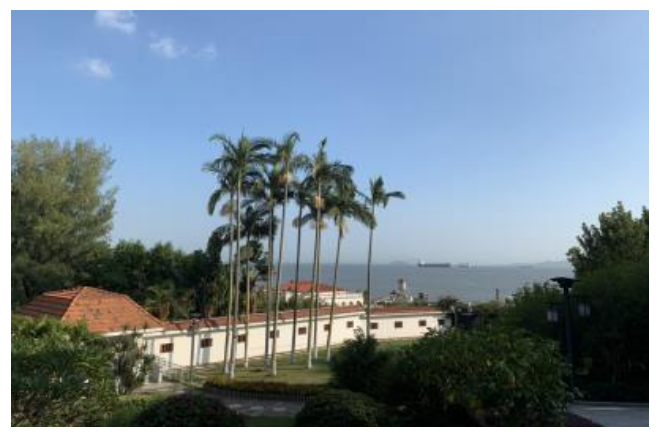

Figure 1 Back sea view of Shuzhuang Garden

Culture permeates gardens, and gardens also reflects the evolution of culture. Private gardens in southern Fujian are an important part of the cultural heritage of Chinese gardens. The large amount of cultural information and heritage value of its own needs to be excavated and demonstrated through scientific research [ 3].

\section{SPATIAL COMPOSITION ANALYSIS}

Space exploration has always been an eternal topic. Compared with other activity spaces, the garden space has its own unique characteristics. The garden space highlights the natural appearance and organic form, and its spatial elements rely on natural elements such as mountains, water, stones, plants, etc., and are not entirely constructed by humans. The boundary of the garden space is often very wide, and the space in the garden is not very obvious. The integration of space and space is mostly connected by "corridors" and "walls" as divisions to show the landscape levels in the garden; pavilions and buildings are mostly gardens. The main interior scenery and the water and stone scenery mainly meet the needs of landscape viewing, which implies the change of space. And the characteristics of the garden are affected by the seasonal climate, and the garden landscape extends with time ${ }^{[4]}$.

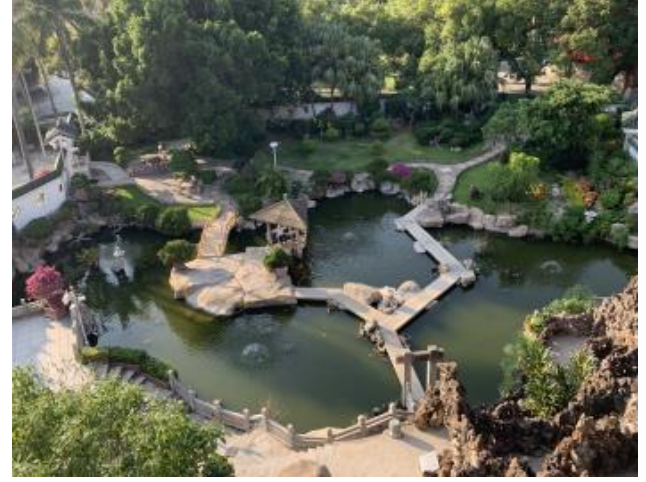

Figure 2 Part of southern Fujian Garden Sketch

Research on the spatial composition of private gardens in southern Fujian needs to rely on the selection of space, the creation of layout, space elements and other aspects to explore the summary, the design of southern Fujian garden culture, planning research also has a very positive significance.

\subsection{Spatial Analysis Of Site election}

Xiamen and Zhangzhou are located in the lower reaches of the Jiulong River. The island of Xiamen has been the center of political, economic, military and cultural development in southern Fujian since ancient times, and since the Tang Dynasty, inland populations have been moving in, and large areas of wasteland have been developed one after another. The geographical advantage of being surrounded by the sea made Xiamen's gardens built with the mountains at their backs and facing the sea. The development of private gardens in Fujian flourished in the Ming and Qing dynasties, and after the Opium War, Xiamen was forced to open a concession area as a port of commerce, and a large number of colonial influx made the garden design gradually westernized, with only a dozen Western-style villas and Southern-style buildings on Gulangyu Island. The private gardens in Xiamen in modern times are mostly built around the sea and located in front of western-style foreign buildings, and the garden is built with a blend of traditional garden construction methods and the influence of western aesthetics, combining East and West.

Zhangzhou was not developed until the Tang and Song dynasties for political and war reasons, and was built in masonry. In the late Ming Dynasty, Zhangzhou's economy became richer and richer, and overseas trade developed, with records of private gardens in Zhangzhou also began in the Ming Dynasty, but the development of private gardens in Zhangzhou started late, and there are only a few intact courtyards[1]. Zhangzhou in the Ming Dynasty at the very beginning of the garden for a total of lectures built by the study or study house, depending on the mountain and water, the size varies, the site in line with the leisurely seclusion demanded by the literati lectures at the time. Zhangzhou 
in the Qing Dynasty, a large number of tulou, tulou fortress also has a study garden, to meet the traditional sense of family living, meeting guests, social needs, etc., Zhangpu County Zhao family fortress garden is as the owner of the garden study. Later, with the introduction of foreign cultures, the style of private gardens built in Zhangzhou during the late Qing Dynasty also reflected the collision and blending of Chinese and Western cultures.

The Min River water system originates from the Wuyi Mountains and other mountain ranges. Quanzhou, downstream of the Jin River, has developed well politically and economically since the Tang Dynasty, with the plains being developed and expanded, and the water system developed to the advantage of the local harbor, which led to the flourishing of overseas trade. During the Yuan Dynasty, the foreign population began to flow into Quanzhou, and expatriates lived there and built gardens. After the Ming and Qing Dynasties, most of the private gardens in Quanzhou were built by the scholars and the great men. Although they were restricted by the ritual system and feng shui, they were influenced by the Western style of gardening and cultural import, and they began to arrange courtyards in front of and behind their houses. The location and layout of private gardens in Quanzhou were mostly concentrated in the center of the ancient city, with "Meishan Shifang", "Huangzhai Xiaoyuan", "Shi Lang Chengpu" and "Shi Lang Dong Yuan", the distribution of which played an important role in building the urban pattern of modern Quanzhou.

The traditional private gardens in southern Fujian mainly rely on the natural topography and rich water resources of southern Fujian, applying natural resources to the construction of the gardens and attaching importance to the use of landscape elements and topography, the space is relatively well laid out and organised ${ }^{[5]}$. The traditional way of building gardens and the ideological and cultural concepts influenced the location, orientation and volume of gardens; the integration of foreign cultures not only influenced the decoration and structure of gardens, but also had an irreplaceable influence on the concept of gardening in terms of spatial composition and the use of materials.

\subsection{Space Construction Layout}

In the cultural environment of traditional Chinese rituals and Buddhist, Confucian and Taoist thoughts, the layout design of gardens is also being influenced in a subtle way. In the case of Fujian's southern Fujian region, the layout thinking of garden building came from the perception of landscape aesthetics on the one hand, and was influenced by the pluralistic ideology and culture on the other.

Private gardens in southern Fujian mainly highlight the natural landscape scenery, and the Chinese have unique insights into the aesthetics of natural landscapes. Smallness, reality, and movement are all shown in the spatial layout of the gardens. Even though the introduction of Western culture in the late Middle Ages influenced the design of some of the gardens in Southern Fujian, the garden builders still retained their knowledge of landscape aesthetics. Since ancient times, the idea of "living off the sky" in Chinese agrarian society has made people rely on nature and believe in nature, so the idea of building gardens focuses on the idea of being close to nature and the unity of nature and man.The private home forest, as a closed courtyard space, is a subtle method of spatial layout in the Chinese concept of the neutral and introverted.

The plan layout of private gardens in southern Fujian is relatively simple ${ }^{[6]}$, relatively scattered and of different sizes, with a variety of spatial construction layout techniques. The layout of space between buildings and landscape is smooth, with pavilions, walls, doorways, bridges and greenery separating the garden areas in order to have a degree of twists and turns. The small courtyard of the Yellow House in Quanzhou, the eastern part of the courtyard along the wall to make rocks, under the open curved pool, the fence turns the arrangement of rocks overlapping into peaks, higher than the wall, decorated with green plants, ornamental effect is very good.

Steps move and scenery change, people follow the scenery. The landscape of private gardens in southern Fujian is set up according to the scenery, using the topography to form a good orientation and create different spatial environments through reasonable division and connection. As mentioned in "Garden Ye", "the idea is in the brush first", the private gardens in southern Fujian often half-hide and half-reveal the idea in the spatial layout, thus increasing the depth of the landscape ${ }^{[7]}$. In the Yizhu Villa on Gulangyu Island, there is a Chinese garden on the right side of the villa in the main building, with paths set up according to the difference in terrain, winding to the octagonal pavilion in the depths for people to relax and watch the scenery.

The migration of the Middle Kingdom's scholar culture, the layout of private gardens in southern Fujian on the basis of the original folklore in a lineage of the Middle Kingdom culture, highlight the original garden style of southern Fujian, with obvious regional characteristics.

\subsection{Research On Space Elements}

The construction of the garden space is not simply a pile of buildings and materials, and there is no great difference between the private gardens of southern Fujian and the private gardens of China in the traditional sense in terms of spatial composition, but the main 
difference comes from the integration of foreign and Chinese cultures.

\subsubsection{Architectural Elements}

Architecture is an important element in the physical space of a garden, it's also an important physical element of the garden space ${ }^{[8]}$, and common types of architecture include pavilions, pavilions, halls, etc.

Southern Fujian traditional private garden pavilions are mostly seen in high places for overlooking purposes, pavilions of such single buildings are mostly attached to the garden around, or hidden in the secret place to do leisure view of the small building use. Such as the imperial book building in Quanzhou Chengpu, late Yuanzhai in the preservation of the listening to the moon building. Pavilion is generally relatively independent and complete image, the pavilion can stand in the mountains or the top of the mountains, can also stand in the water to increase the viewing distance, to meet the needs of the landscape in the garden, many paintings can also be seen in the pavilion point scenery or pavilion as the main scenery.

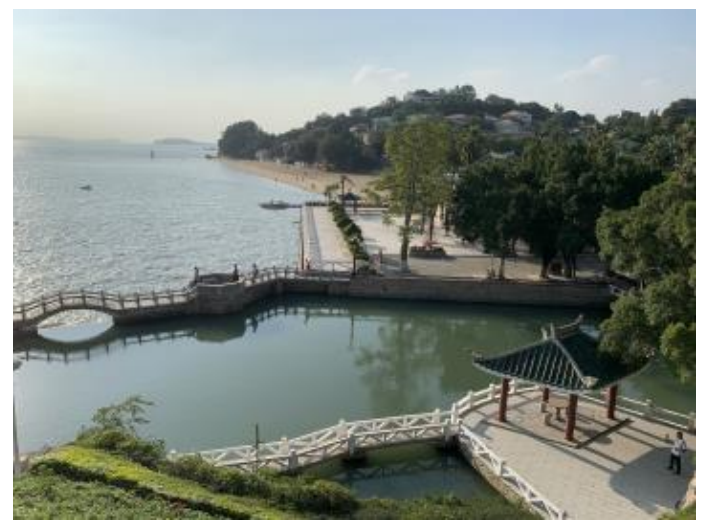

Figure 3 The Pavilion Gallery

There are many types of covered bridges. The main function is to serve as a bridge connecting the buildings in the garden, which can divide the water surface and increase the spatial level. The "Forty-Four Bridges" in the Shuzhuang Garden are useful for this purpose. The hall is generally the main building. On the central axis of the park, it is mostly used by the host to meet guests. The gorgeously furnished hall in the southern Fujian garden becomes the "flower hall", and the roof has two types: Xieshan top and hard top.

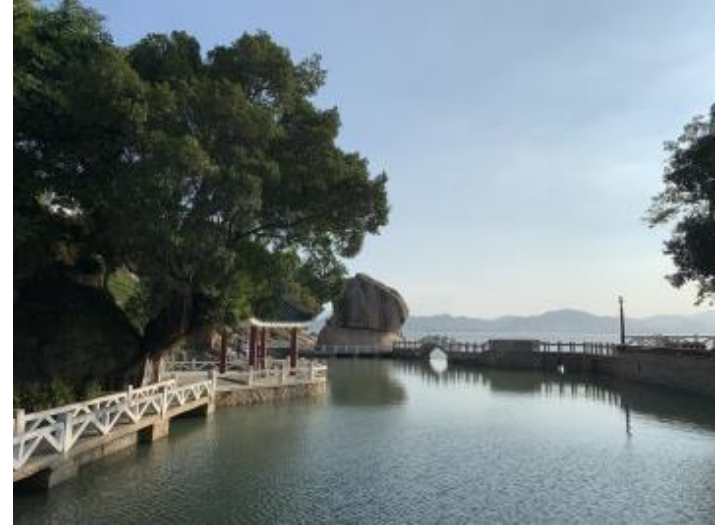

Figure 4 Part of "Forty-Four Bridges"

\subsubsection{Landscape Elements}

The landscape elements mainly include some garden vignettes. With the natural environment of real mountains and water in southern Fujian, the gardening also pays much attention to the close combination between mountains and water.

Garden stacked stones is a timeless and unchanging landscape element in traditional Chinese gardens, and private gardens in southern Fujian, whether Chinese, Chinese and Western, or Western-style gardens of all kinds, pay particular attention to the landscape of mountains and rocks. In the stone collection mountain often have green plants echo embellishment, pool combination, the Chinese cultural concept, the mountain for the skeleton of the garden, plants and water is the mechanism. Retaining the natural state of the stone can be integrated into the landscape to express emotions in addition to the ornamental function. The application of plant configuration in the garden not only has an ornamental role but also has the function of landscape composition.

Minnan private garden landscape between the beauty of the rich layers, with the scene lining the scene, superior natural conditions for the formation of landscape elements of the garden provides good conditions, Zhangzhou's Guteng Xian Pavilion in the wigwam completely leaning on the east wall of the garden, a huge area, the pool and the cliff cave connected, with an arched bridge, the landscape effect echoes. Water elements in southern Fujian private gardens are mostly presented in static form seeking natural seclusion, stretching and gentle, but Western-style gardens are mostly fountain vignettes are not like traditional gardens in the use of pools, streams to create a change in the extension of space, through the reflection of the water surface, increasing the landscape ornamental levels. 


\subsubsection{Decorative Elements}

The decorative elements of traditional private gardens in southern Fujian are mainly sculptures. Many characteristics of the sculpture itself include nationality, religion, and times. Affected by ideology and culture, the content of sculptures often carries meaning. Traditional gardens are decorated with auspicious patterns on the roof, and the palace-like ancient house is covered with red tiles. The sculpture subjects are diverse; the decorative elements brought by the immigrants after the Ming and Qing Dynasties are in the private gardens of southern Fujian, such as ancient Greek column decorations, embossed branches, sculptures on the walls, etc., paying more attention to the decoration of the building facade.

Except for architectural decoration, the ground paving also relies on Minnan culture and Western culture. The characteristic of Chinese gardening roads is "the winding path leads to tranquility". There are twists and turns on flat ground, roundabouts on water corridors, and roundabouts on high ground, which greatly enriches the decorative function of garden roads and creates harmony with the environment. The garden scenery ${ }^{[9]}$; Western gardens have a simple style of paving and a clear sense of direction. The simplified ground paving sets off the complex decoration of the building.

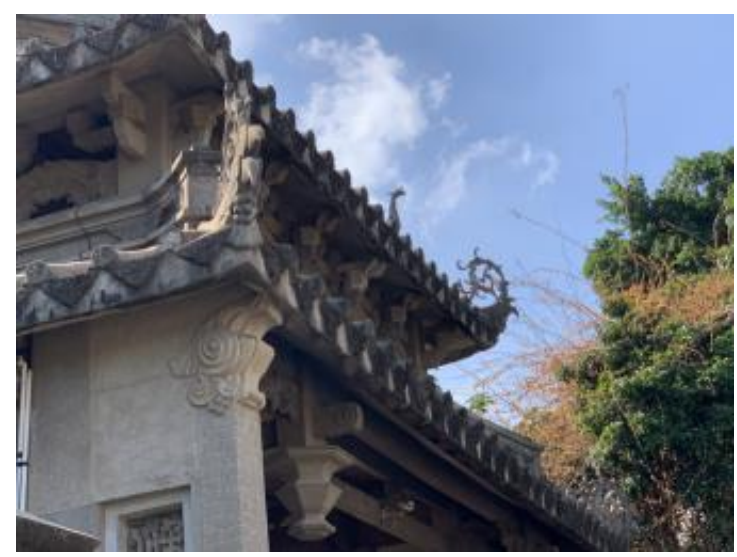

Figure 5 FEI YAN of garden buildings

\section{THE CULTURAL CONNOTATION OF THE SPATIAL COMPOSITION OF TRADITIONAL PRIVATE GARDENS IN SOUTHERN FUJIAN}

The spatial composition of private gardens in southern Fujian is permeated with a very rich cultural connotation, and the gardens in southern Fujian are a voluminous cultural complex that combines multiple cultures. The artistic style of the garden space also reflects the exchange and clash of cultures ${ }^{[10]}$.

Private gardens in southern Fujian were formerly known as private academies throughout southern Fujian, so the most initial cultural connotation is a product under the culture of academy gardens. The emergence of the academy was a need for education and a gathering place for ideas, so it was bound to carry the history and culture. In the process of transforming into private gardens, the Southern Fujian academy has precipitated various cultures that have been incorporated over the centuries, and has also witnessed the inheritance and changes of the cultural connotation of the Southern Fujian region. From the viewpoint of the basic cultural characteristics of southern Fujian culture, it has the inclusiveness of accepting all rivers, the aggressiveness of development and innovation, and the openness of courage to expand, and these characteristics are used in the creation of private garden space, which greatly enriches the cultural connotation of southern Fujian garden.

From a cultural perspective, the integration of cultures injects cultural connotations into the private gardens of southern Fujian. The initial construction of the gardens was based on demand and ornamental purposes, and the cultural elements are amplified in the manifestation of the spatial composition with the differences in the ideology of garden building. The cultural system of private gardens in southern Fujian consists mainly of two parts: traditional cultural concepts and the culture of social change. The structure of the inheritance of traditional cultural concepts in southern Fujian is quite complex, and the influence of the erosion of foreign culture, culture in the process of inheritance may fade at any time, the private gardens in southern Fujian still retain the connotation of traditional culture in the spatial composition, the degree of difficulty cannot be overstated. Social change is related to ideological change, political economy, etc. Social change is ultimately about what changes have occurred in society and what results from the series of chain reactions brought about. This cultural system of social change is reflected in the private gardens of southern Fujian, which range from the original school landscape to the private gardens of various eras, to the private gardens of traditional and Western cultures arising from the collision of Chinese and Western cultures, and finally to the Western-style houses of the colonial era. Each social change brought new cultural connotations, which in turn contained complex generative elements.

Cultural changes are all about adapting to the changes in the environment they are in. Guided by the concept of traditional culture and passing on cultural memories, the private gardens in Southern Fujian have formed their own system, inherited and recreated. The gardens built in Xiamen during the colonial period were often attached to foreign buildings and villas, and the style was compatible with the East and the West; the Tao Yuan Garden in the Tian Yi Xin Bureau has pavilions, ponds, rockeries, shining walls and couples, all of which are traditional Chinese cultural contents, but the main building, the Tao Yuan Building, is a foreign building 
with an ancient Greek coupon-columned outer corridor with a distinctly Western style.

\section{CONCLUSION}

This paper analyzes the spatial composition of private gardens in southern Fujian from a cultural perspective, focusing on the site selection, layout, elements and cultural connotations of their spaces through a brief laying out of the history and current situation of southern Fujian gardens. Culture is an important part of gardens, and the development and changes of culture affect the development and changes of gardens. Minnan culture is typically formed by the collision of Chinese and foreign cultures, but the traditional garden elements have lost their original symbolic meanings to a certain extent, so much so that post-modern Minnan gardens have undergone deep structural changes.

Under the impact of Chinese and Western cultures, the evolutionary process of private gardens in southern Fujian is inherited, variation and innovation, and it is not easy to be preserved until now, after the cultural heritage formed by the baptism of many cultures and centuries of history, it is different from Jiangnan gardens with a large audience and deep research, but inheritance and preservation are very necessary. In fact, analyzing the gardens of southern Fujian from a cultural perspective, one can go further to dissect the culture of the landscape, the culture of the elements, etc., and explore the patterns between the landscape and the modeling composition, etc. Southern Fujian private gardens have witnessed the socio-political, economic and cultural development changes in the southern Fujian region since the developed Tang and Song dynasties to the modern times, and have an important role and positive significance for the study of contemporary garden construction and the planning and design of urbanization in China.

\section{REFERENCES}

[1] Cao, C.P. (2013) Private gardens in Fujian and Taiwan. Tsinghua University Press, BeiJing

[2] Li, X. (2020) Research on modern Urban Landscape of Kaifeng. Henan University, KaiFeng.

[3] Zhu, R, Wang, W.J, Wang, C. (2017) A study on the characteristics of modern gardens in Wuxi. Chinese Gardens, 33, 3:6.

[4] Yin, R. (2019) Study on the spatial composition of classical gardens in Suzhou. University of Science and Technology of Suzhou, SuZhou.

[5] Wang, J.H. (2020) Study on the Characteristics of Modern Garden Design in Nanjing. Jiangnan University, WuXi.
[6] He, Z.R. (2016) The Construction Theory of Ancient Min-nan Traditional Gardens. Guangdong Gardens, $38,2: 4$.

[7] Huang, Y.L. (2021) Exploring the characteristics of traditional gardening in southern Fujian. Fujian Building Materials, 7:42-44.

[8] Wang, H.C. (2020) Study on the Space of Huizhou Private Garden in Ming and Qing Dynasties. South China University of Technology, GuangZhou.

[9] Gu, R.X. (2020) A comparative study of Chinese and Western classical garden design culture. Anhui University of Engineering, WuHu.

[10] Zhang, Z.X. (2019) On the Blending of Chinese and Western Garden Culture fromModern Gardens in Southern Fujian, Journal of Langfang Teachers College, 2019, 1:4. 